SHORT COMMENTARY

\title{
Breast Injury During Sport Participation
}

\section{Laura J Smith ${ }^{1 *}$, Tamara Eichelberger ${ }^{2}$, Elizabeth Miller ${ }^{3}$ and Edward J Kane ${ }^{4}$}

${ }^{1}$ Assistant Professor, University of Michigan-Flint, USA

${ }^{2}$ Assistant Professor, Azusa Pacific University, USA

${ }^{3}$ Student, University of Michigan-Flint, USA

${ }^{4}$ Professor, University of St. Augustine for Health Science, USA

*Corresponding author: Laura Smith, PT, DPT, PhD, Associate Director, Post Professional Clinical Professional Development, University of Michigan-Flint, 2157 William S. White Building, 303 E. Kearsley Street, Flint, MI 48502-1950, USA, Tel: 810-762-3373, Fax: 810-766-6668

\section{Introduction}

A recent study found that almost half (47.9\%), of female college athletes participating in basketball, soccer, volleyball and softball $(n=194)$ suffered a breast injury during their college career with less than $10 \%$ reporting their injury to health personnel with only $2.1 \%$ receiving treatment [1]. Breast injury in female athletes is under-reported and is lacking a much-needed level of awareness in sport. If there is a void in awareness of breast injuries and in reporting breast injuries, preventive measures as well as any potential sequela from the injury will not be given the necessary attention.

Reporting athletic injuries commonly follows a formalized and effective process depending on the athletic environment. The National Collegiate Athletic Association (NCAA) Injury Surveillance Program (ISP) has three criteria for a reportable injury/trauma: injury occurred as a result of participation in an organized intercollegiate practice or contest, injury required medical attention by a team certified athletic trainer or physician, and injury resulted in restriction of participation or performance for at least one day beyond the day of injury/trauma, with athletic trainers voluntarily reporting injuries to the database/NCAA [2]. Perception of injury is an integral part in the decision to report an injury [3]. For example, athletes that perceive an injury as minor may not report because they might believe it will resolve on its own and is not worth risking playing time to report. A reason for perceiving injuries to be less severe could be from lack of knowledge and awareness of the specific ailment. For an injury to be reported, athletes must have enough education of multitudes of injuries, predict positive consequences to sharing their injury, risk playing time, and the injury must fulfill the NCAA ISP's criteria. Currently, for a breast injury to get reported to the ISP, the breast injury must meet the criteria established by the NCAA ISP, the AT must be informed of the injury, and the AT must enter it into the ISP database. Therefore, a likely gap exists for breast injuries to be missed. Given that $10 \%$ report their injuries [1], without reporting injuries, awareness of injuries and thus preventative measures for them will not be undertaken.

The potential long-term sequela of breast injury occurring during sport participation is not known [1]. Conversely, case studies and research done after falls, motor vehicle collisions (MVC), and surgery provide strong evidence of sequela of breast injury [4-9]. Blunt force or laceration injuries resultant from an MVC, surgery, or a fall can result in milk-duct injury [4], hematoma and pain [5], fat necrosis [6], asymmetry [7], or damage to the nervous innervation of the mammary region along with scar tissue formation [8]. Sport activities present ample opportunities for blunt force and laceration injuries by collision with another player, sport equipment, or the environment. To increase reporting of breast injuries in sport, evidence of potential sequela after injury to the breast should be used as a foundation for educating female athletes and medical professionals on the importance of seeking treatment for their breast injury sustained during sport activities.

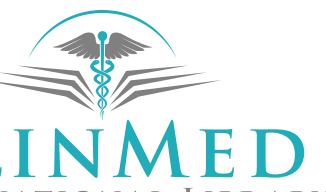

INTERNATIONAL LIBRARY

Citation: Smith L, Miller E, Eichelberger T, Kane EJ (2018) Breast Injury during Sport Participation. Int J Sports Exerc Med 4:112. doi.org/10.23937/2469-5718/1510112

Accepted: December 24, 2018; Published: December 26, 2018

Copyright: (c) 2018 Smith $\amalg$, et al. This is an open-access article distributed under the terms of the Creative Commons Attribution License, which permits unrestricted use, distribution, and reproduction in any medium, provided the original author and source are credited. 
A retrospective analysis of female blunt breast trauma (FBBT) at a level 1 Trauma center revealed that the majority (94\%) of FBBT was from MVCs [9]. The authors recommended specific treatment guidelines for those with active bleeding and recommended that some patients may need to be handled individually based on their injury [9]. Additionally, following a systematic review [10] of seat belt injuries to the breast, the authors suggested that in the acute setting immediately following the injury all patients should undergo chest radiography in order to rule out fracture, be given analgesics as needed, and any necessary wound dressings. They also fond that $69 \%$ of patients who did not receive treatment in the acute setting sought treatment later for painful lumps or deformities [10]. Patients who were not managed conservatively after the injury sought treatment later for chronic problems and required surgical excision, mastectomy, surgical replacement of an implant, or breast reconstruction. The authors recommended that these patients be given a clinical exam, imaging, and fine-needle aspiration or biopsy [10]. Both of these reports underscore the need for immediate attention to breast injury, including the appropriate treatment and routine follow up for any potential sequela. While the psychological effects of breast trauma in sports has not been explored, reports of long-term pain and anxiety were reported in a woman after breast trauma from MVC [11].

Educating female athletes on the severity and impact of breast injury may not be enough to get them to report if they feel their complaint will not be taken seriously or dealt with appropriately. Educating athletes must be paired with educating athletic trainers, physical therapists, coaches, and physicians on the importance of taking breast injury sequela seriously. Another suggestion to increase awareness of breast injury is to create a specific way to document breast injury that accurately portrays the mechanism of injury, severity, time off, and treatment. Documenting sport related breast injuries may appropriately set these sensitive injuries apart from broad trunk injuries and give sport medical professionals a reference for diagnosis. Female athletes may not understand the severity of their breast injury, may think it will go away on its own, not want to risk losing playing time, feel uncomfortable talking about breasts, or may not want to seem weak [3]. Consequently, a sports medical professional can only treat an injury with which they are familiar. In general, guidelines for management of athletes is commonly driven by data of reported injury, and if injuries are not reported little can be done to advance the overall management and care. The discussion of sport related female breast injury is multifaceted and should be considered an opportunity to enhance the overall care for female athletes by coaches and the team medical staff. More awareness is needed for the potential to sustain a breast injury during sport participation, but also for monitoring for any potential sequela from the injury.

The evidence supporting sport related female breast injury is sparse. One general recommendation is that more research is needed in all aspects of breast injury. Specifically, female breast health education and injury management should be a priority of sport related medical professionals, coaches, and female athletes. Attitudes toward breast injury should be re-evaluated and address the needs and overall health of the modern-day female athlete. Female athletes may be more at ease reporting and receiving care from an Athletic Trainer of the same gender [12]. Coaches and the professional medical team should work with female athletes to create an environment that invites an open dialogue about breast injuries and is committed to breaking the silence about these under-reported injuries [1].

\section{Funding}

None.

\section{Conflict of Interest}

None.

\section{References}

1. Smith LJ, Eichelberger TD, Kane EJ (2018) Breast injuries in female collegiate basketball, soccer, softball and volleyball athletes: Prevalence, type and impact on sports participation. Eur J Breast Health 14: 46-50.

2. Kerr ZY, Comstock RD, Dompier TP, Marshall SW (2018) The First Decade of Web-Based Sports Injury Surveillance (2004-2005 Through 2013-2014): Methods of the National Collegiate Athletic Association Injury Surveillance Program and High School Reporting. J Athlet Train 53: 729-737.

3. Jessica Suzanne BM (2018) Social psychological influences on sport-related injury reporting of collegiate studentathletes. Indiana (PA), Indiana Univ of Pennsylvania.

4. Sircar T, Mistry P, Harries S, Clarke D, Jones L (2010) Seat-belt trauma of the breast in a pregnant woman causing milk-duct injury: a case report and review of the literature. Ann R Coll Surg Engl 92: 14-15.

5. Madden B, Phadtare M, Ayoub Z, Chebl RB (2015) Hemorrhagic shock from breast blunt trauma. Int J Emerg Med 8: 83.

6. Akkas BE, Ucmak Vural G (2013) Fat necrosis may mimic local recurrence of breast cancer in FDG PET/CT. Rev Esp Med Nucl Imagen Mol 32: 105-106.

7. Jansen DA, Stoetzel RS, Leveque JE (2002) Premenarchal athletic injury to the breast bud as the cause of asymmetry: Prevention and treatment. Breast J 8: 108-111.

8. Ducic I, Zakaria HM, Felder JM, Fantus S (2014) Nerve injuries in aesthetic breast surgery: Systematic review and treatment options. Aesthet Surg J 34: 841-856.

9. Sanders C, Cipolla J, Stehly C, Hoey B (2011) Blunt breast trauma: is there a standard of care? Am Surg 77: 1066-1069.

10. Song CT, Teo I, Song C (2015) Systematic Review of seat-belt trauma to the female breast: a new diagnosis and management classification. J Plastic Reconstruction Aesthet Surg 68: 382-389.

11. Majeski J (2001) Shoulder Restraint Injury to the Female Breast: A Crush Injury with Long-Lasting Consequences. J Trauma 50: 336-338.

12. Drummond J, Velasquez B, Cross R, Jones M (2005) SelfReported Comfort in Athletic Training of Gender-Specific and Non-Gender-Specific Injuries and Issues. J Athlet Train 40: 211-217. 